\title{
Determinants of Academic Staffs Participation in Research Activities in Ethiopian Universities: The Case of Wollega University
}

\author{
Abebe Shanko \\ Department of Management, Wollega University, PO box 395, Nekemte, Ethiopia \\ Firdisa Birru \\ Department of Economics, Wollega University, P.O.Box 395, Nekemte, Ethiopia
}

\begin{abstract}
Undertaking more research is widely considered as the most as it leads to creation of new knowledge, inventions and innovations in Sub-Saharan Africa in general and in Ethiopia in particular, yet there are very few studies of the extent to which it fulfills this promise. In this paper we use survey data from Wollega University to understand the factors hindering research participation decision of academic staffs at university level. Faculty members' participation in research helps in improving the quality of teaching faculty and the status of an institution. Decisions about promotion and tenure heavily rely on the quality and quantity of research productivity. A selfadministered questionnaire has been used to gather data. The sample size comprises of 120 faculty members from two selected colleges. Data has been analyzed by using statistical techniques and logit model. We conclude that availability of publication incentives, work experience, speed of internet, accessibility to research funds and colleague collaboration on research participation all enhance the probability of academic staff's research participation while teaching load is negatively related to the probability of academic staff's research participation in the study area.
\end{abstract}

Keywords: Research, Research participation decision, Institutional factors, Environmental factors, Personal career development factors, Demographic factors.

DOI: $10.7176 / \mathrm{DCS} / 11-1-02$

Publication date: January $31^{\text {st }} 2021$

\section{Introduction}

1.1. Background of the study

Research participation is the amalgamation of research and participation. Research is a search for knowledge and participation is a categorical variable which shows whether a respondent has a published and/ or unpublished research during specific time period. Various researchers have studied and checked the relationship between research productivity and the factors that determine research productivity in both private and public Universities (Mazzucato, 2013, Musiige, 2012). Previous studies have mainly focused on investigating the relationship between publication productivity and variables such as institutional size (Matthews D., 2016), academic rank (Hedjazi and Behravan, 2011), age and gender (Mamiseishvili, K., Rosser, V., 2011; Babalola, G. A., 2014).

The most frequently found as significant institutional factor that influences participation in research activity was the proportion of time for conducting research compared to other works, such as teaching, community services and administrative tasks. Universities play a vital role in allowing staff members to have less time for teaching so that those staff members can do researches ( White et al., 2012;Webber, 2012), and it is considerably connected to research productivity (Sulo et al., 2012; McGill \& Settle, 2012; Webber, 2012; Shariatmadari \& Mahdi, 2012; Jung, 2012). It is found those staff members who reported involvement in administrative activities (Abouchedid, K. \&Abdelnour, G., 2015) and having heavy teaching loads (Hesli \& Lee, 2011) were less likely to participate in research.

It is important to learn from countries such as the United States of America, which has successfully built its academic research capacity within and outside the university, yielding many positive results, including a more innovative industrial sector and better technical skills in the workforce than any other nation in the world (Mazzucato, 2013). The study conducted by Jung (2012), shows that individual characteristics included years of experience; workload included time spent to teaching, time spent conducting research and instruction time for doctoral programs; research style included research preference, collaboration, applied and multi-disciplinary research; and institutional characteristics included performance-based management, commercial orientation, and shared governance affect academic staffs' participation in research (Edgar and Geare, 2013). Educational qualification is another important personal factor that could affect research productivity of academic staff as pointed out by Fennewald, J. (2012). In the study carried out on librarians in colleges of education in Nigeria also identified educational qualification(s) as a significant influence on research productivity (Babalola, G. A., 2014).

According to Habtamu (2018), teaching and research are equally important for university instructors so that 
they must give equal attention to research and teaching as a part of their duty, because participation in research directly improves the quality of teaching. Despite the fact that research productivity is one of the requirements for every lecturer in any university, there has been low turn up of lecturers to participate in writing and publishing research works especially in African universities (Ubogu F \& Van den Heever M, 2014; Maassen P, 2012; Ogoti E., 2018). Furthermore little is known about participation in research in academic institutions in developing countries like Ethiopia and the available literature was conducted in developed countries. According to Teka F\& Habtamu D, (2018), it is believed that faculty publication output is very low in majority of Ethiopian higher institutions, particularly in the new generation universities.

\subsection{Objectives of the study}

The ultimate objective of this study is to identify and analyze major demographic, socio-economic and institutional factors impeding deepening of faculty members' participation in research work in Wollega University and through that make recommendations to improve the effectiveness of interventions. The specific objectives are:

- assess the level of awareness of faculty members on the participation and significance of research to improve the quality of teaching faculty and the status of an institution.'

- identify and analyze the factors those determine faculty members' participation in research activities.

- Analyse the extent to which determinant factors hinder faculty members' participation

\subsection{Working hypothesis}

Academic staffs in the Ethiopian Universities are characterized by heterogeneity in various aspects of livelihoods like differences in age, knowledge of research practices, teaching load, participation in national workshops, degree of collaboration in research work and etc which could lead to differences in their participation in research activities. The following hypothesis can be tested using the Likelihood ratio test: $L R(\lambda)=2$ (ULLF - RLLF), Where, ULLF and RLLF are the values of unrestricted log-likelihood function under H1 and that of the restricted log-likelihood function under Ho, respectively (Gujarati, 2004). The null hypothesis is rejected if the calculated chi-square is over than the critical chi-square with degrees of freedom equal to the number of restrictions at $1 \%, 5 \%$ or $10 \%$ level of significance i.e. LR $>\chi \mathrm{c}^{2}$ (Greene, 1992 and Woodridge, 1993). If the sample size is large the test statistic $\lambda$ follows the chi-square $\left(\chi^{2}\right)$ distribution with degrees of freedom equal to the number of restrictions imposed by the null hypothesis.

We can formulate the following null hypotheses:

1) The hypothesis that chooses the appropriate functional form for binary logit model that can adequately represent the data was tested. $\mathrm{H}_{0}: \beta_{1}=\beta_{2}=\ldots \ldots=\beta_{14}=0$. The coefficients of the predictor variables are simultaneously zero against $\mathrm{H} 1$ : the above coefficients of explanatory variables in binary logit model are statistically significantly different from zero meaning that the explanatory variables are important in the model.

2) Participation in research activities does not vary interms of mean teaching load and work experience-in years.

3) Participation in research activities does't vary interms of institutional factors: availability of publication incentives, accessibility to research funds, teaching load in hours, promotion and availability of national workshops.

4) The hypothesis for the joint significance of age and gender of respondent.

\section{Related literature}

There are a number of reasons identified why academics do not participate in research writing for publication (Angaiz, D. 2015; McGrail, Richard \& Jones, 2016). The studies by Jung (2012) and Zhou (2014) on determinants of research participation found that age, gender, experience, academic rank, time, teaching load, research competency and interest in doing research and availability of training realted to research are significantly influencing academic staffs participation in research work. The number of years of experience is a significant predictor of participation in research (Jung, J., 2014). Senior professors have already accumulated a certain degree of academic capital and momentum in order to participate in research writing and publishing (Chandra, 2018). Since tenured professors tend to publish more than non-tenured (Zhou \& Volkwein, 2014), academic seniors are more inclined to a higher level of research writing than those at the lower rungs of the academic ladder.

A number of investigations have been undertaken to explore the determinants of academic staffs' participation in research writing. Differences in participation in research writing have been explained in terms of age, gender, ambition, motivation and self-esteem (Belay \& Reji, 2016), previous experience, training (Bazeley, P, 2010; Hora; Merera \& Jalel, 2019), mission, colleagueship governance, reward system (Jung, J. 2014; Frantz J. M., A., Phillips J. 2016), and teaching load (John, 2017; Shimelis \& Fayera, 2018). Female academics participate less than their male counterparts, which might be explained in terms of female's social roles somehow impeding their decision to participate in research (Adugna \& Tariku, 2017). Teaching load appears to influence decision to participate in research. Teaching load is generally measured by the amount of time devoted to academic activity, and this time 
has amplified as the roles of academics have become more multifaceted and different.

Bunting I (2014a) found that the availability of student research assistance; financial incentives for conducting research; and access research funds affect participation in research writing. Similarly improved research management, modern infrastructure, promotions stimulate the probability of academic staff members' participation in research (Ubogu \& Heever 2014). Bazeley (2010) and Cloete et al. (2011) identified that education and training, opportunity and resources, lack of funds and a proper incentive system; the absence of $\mathrm{PhD}$ mentorship programs and incentives; and the competition for time between undertaking research and teaching are factors hindering the likelihood of participation in research at Universities and Economic Development in Africa. University teachers' probability of participation in research is determined by marital status, age, teaching load, availability of internet, library, funds, visiting abroad facility, attitude of the administration, attitude of colleagues, personal interest, social activities, institutional policies, financial status, caliber of the academicians, level of job satisfaction (Muhammad Zafar Iqbal, 2011). Female instructors tend to participate less and publish papers in small numbers (Alzahrani, J., 2011, Ogoti Evans Okendo, 2018) and Zeleza P (2014) found that most male academics have higher publishing rates than their female colleagues. Studies show that faculty members' likelihood of participation in research is constrained by ack of institutional research support, lack of library resources (Hoffmann \& Koufogiannakis, 2014); teaching load (Webber, 2011; Alghanim, \& Alhamali, 2011; Jung, 2012); colleague collaboration on participation (Shin \& Cummings, 2010) and faculty preferences (Mamiseishvili \& Rosser, 2011, Jonathan M. at el, 2017).

Figure 1: Conceptual Framework

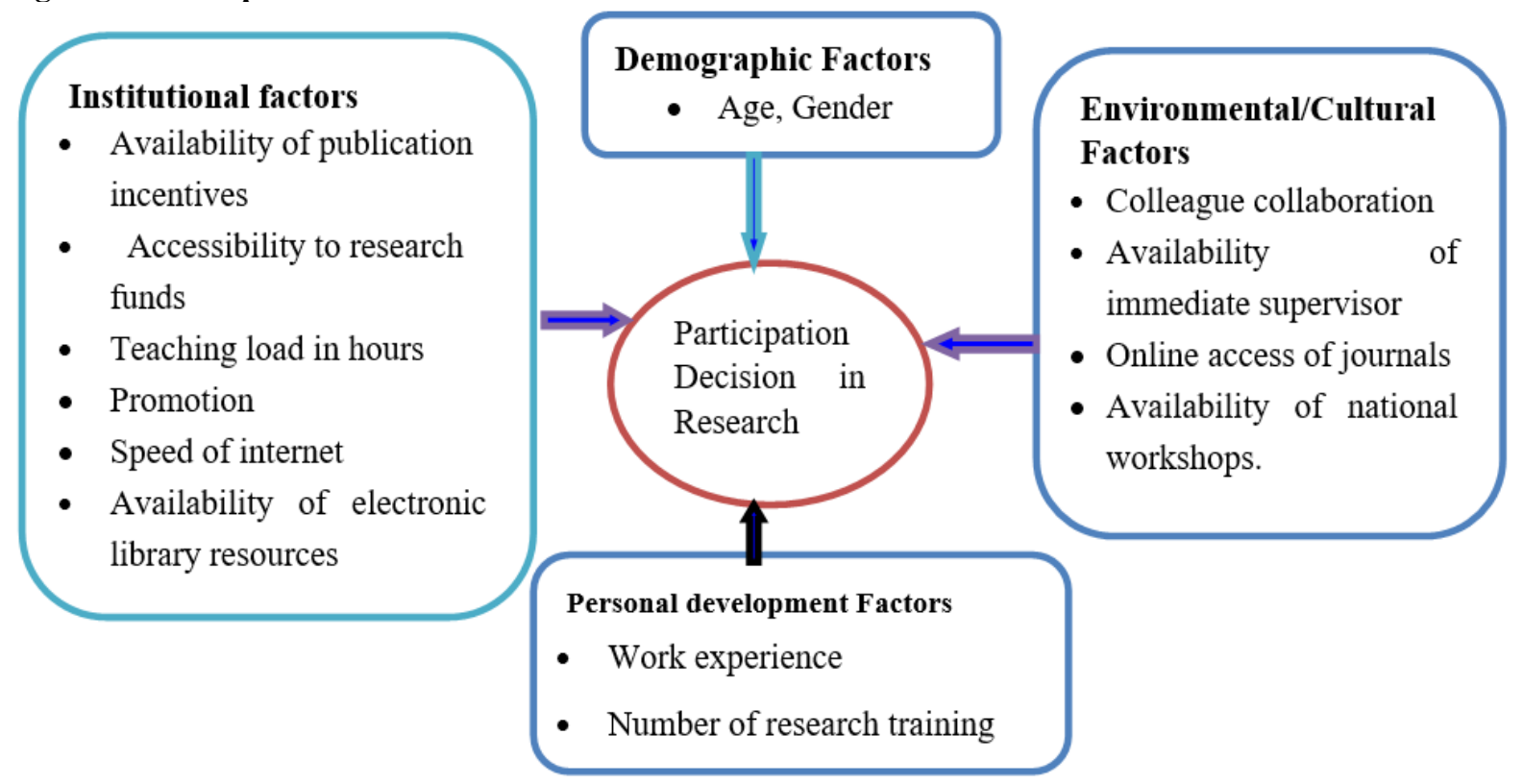

Source: Developed from Literature and own knowledge

\section{Materials and Methods}

\subsection{Description of the Study area}

Wollega University is a public higher educational institution established in February 2007 by enrolling 851 students in 17 departments under four Faculties: Business and Economics, Education, Natural Sciences and Social Sciences. At the time, the University had 140 academic staff, and about 123 administrative support staff. The Wollega University is located on the verge of Nekemte town, which is $310 \mathrm{~km}$ away from Addis Ababa westwards, with beautiful scenery of landscape and spectacular view of Mount Komto. It is situated on an area of 150 hectares. At present, Wollega University runs 82 undergraduate, 45 graduate programs and $7 \mathrm{PhD}$ programs in the three campuses. WU is an innovative institution and a pioneer University to implement continuous assessment, studentcentered approach and active learning in the teaching-learning area to transform the traditional methods of teaching. Today, Wollega University is a comprehensive University engaged in the provision of all-rounded education, research and community services.

\subsection{Methodology}

To assess the determinants of faculty members' decision to participate in research writing the data was largely based on the primary data, information collected from the 120 sample academic staffs and 6 key informants. Also different literatures via books, journals and articles were important sources of secondary data. Both descriptive statistics and binary logit model were employed to analyze the data. The sampling design that was applied for the 
research is simple random sampling. There are total of 172 academic staffs (64 from College of Business and Economics and 56 College of Engineering and Technology) for this study. Using Miller and Brewer (2003) formula for sample size computation:

$n=\frac{N}{\left[1+N\left(\delta^{2}\right)\right]}$ Where $\mathrm{n}=$ Sample size; $\mathrm{N}=$ Total academic staff in the two colleges; $\delta=$ precision level. Accordingly, the researcher assumed precision level $(\delta)$ of $5 \%$. Then, the sample size is;

$n=\frac{172}{\left[1+172\left(0.05^{2}\right)\right]}=\frac{172}{[1.43]}=\underline{\underline{120}}$

Where $n=120$ is the total sample faculty members were selected for the study.

\subsection{Study period and Study designs}

The study was conducted from April to June 30, 2019. The self administered questionnaire with both open and close ended questions was distributed to respondents in the campus. The questionnaire was used because it limits inconsistency and also saves time.

\subsection{Method of Data analysis}

Raw data was cleaned, coded and entered into the computer using Stata Software. Both descriptive statistics and binary logit model were used to investigate the relationship between the decision of the academic staff to participate and the explanatorory variables. Logit and probit regression functions are nonlinear functions of the coefficients specifically designed for binary dependent variables. According to a leading author, Amemiya, there are no compelling grounds for preferring logit to probit or vice versa. The selection depends on the researchers' own interest. Derivation of the binary logit model begins from the linear probability model of the form:

$$
\begin{array}{r}
P(y=1 / x)=\mathrm{Zi}=\beta_{0}+\beta_{1} x_{1}+\beta_{2} x_{2}+---+\beta_{k} x_{k}--------(1) \\
\boldsymbol{P i}=\frac{\boldsymbol{e}^{\mathbf{z}}}{\mathbf{1 + e ^ { z i }}}
\end{array}
$$

Where, $\mathrm{P} i$ is the probability that the $\mathrm{i}^{\text {th }}$ staff participating in research writing, $\mathrm{z}_{\mathrm{i}}$-is a linear function of $\mathrm{n}$ explanatory variables $(\mathrm{x})$ and will be expressed as:

$$
\mathrm{Zi}=\beta_{0}+\beta_{1} x_{1}+\beta_{2} x_{2}+---+\beta_{k} x_{k}+U i
$$

Where, $\beta \mathrm{o}$ - intercept, $\beta i$ - regression coefficients to estimate, $\mathrm{U}_{\mathrm{i}}-$ is an error term.

$$
1-P i=\frac{1}{1+e^{z i}}
$$

Where $1-\mathrm{Pi}$ is the probability that a faculty member will not participate in research writing.

$$
\left(\frac{\mathrm{Pi}}{1-\mathrm{Pi}}\right)=\left(1+\frac{\mathrm{e}^{\mathrm{zi}}}{1+\mathrm{e}^{-\mathrm{zi}}}\right)=\mathrm{e}^{\left(\beta_{0}+\beta_{1} x_{1}+\beta_{2} x_{2}+---+\beta_{k} x_{k}\right)}-----(5)
$$

This is known as Odds ratio. Taking the natural logarithm of the Odds ratio, the logit model is:

$$
\mathrm{Li}=\ln \left[\frac{\mathrm{Pi}}{1-\mathrm{Pi}}\right]=\ln \mathrm{e}^{\left(\beta_{0}+\beta_{1} x_{1}+\beta_{2} x_{2}+---+\beta_{k} x_{k}\right)}=\beta_{0}+\beta_{1} x_{1}+\beta_{2} x_{2}+---+\beta_{k} x_{k}
$$

Where $\mathrm{x}_{1}, \mathrm{x}_{2},--------, \mathrm{x}_{\mathrm{k}}$ are demographic, institutional and personal factors which were included in the above econometric model.

\section{Results and discussion}

\subsection{Descriptive and Inferential analysis}

From total sample (120), $77(64.17 \%)$ are males and $43(35.83 \%)$ respondents are female academics. The study found that of the total (36) participants $23(63.89 \%)$ are males while the rest $13(36.11 \%)$ are females. Similarly $54(64.29 \%)$ of the non-participants are males while $30(35.71 \%)$ are females. The result revealed that female academics participate less than their male counterparts, which might be explained in terms of female's social roles somehow impeding their decision to participate in research. However, the chi-square $\left(\chi^{2}\right)$ statistics obtained from mean comparison test indicates that there was no significant difference between male and female academics on participation in research. The average age of the academic staff is 41 years with a range of 24 to 60 years. The age structures of the surveyed academic staffs reveal that $49(40.82) \%$ of the staffs are above the age of 40 years while the remaining $71(59.18 \%$ ) are on the age range of 18 to 40 years ( most probably they are young). 
Table 1: Gender distribution of respondents

\begin{tabular}{|c|c|c|c|}
\hline Gender & Freq. & Percent & Cum. \\
\hline Female & 43 & 35.83 & 35.83 \\
\hline Male & 77 & 64.17 & 100.00 \\
\hline Total & 120 & 100.00 & \\
\hline
\end{tabular}

Source: own computation from Survey data (2019)

Table 2: Faculty members' participation distribution by gender

\begin{tabular}{|c|c|c|c|c|c|c|}
\hline \multirow{2}{*}{ Gender } & \multicolumn{2}{|c|}{ Participant } & \multicolumn{2}{c|}{ Non-participant } & \multicolumn{2}{c|}{ Total } \\
\cline { 2 - 7 } & No & $\%$ & No & $\%$ & No & $\%$ \\
\hline Male & 23 & 63.89 & 54 & 64.29 & 77 & 64.17 \\
\hline Female & 13 & 36.11 & 30 & 35.71 & 43 & 35.83 \\
\hline Total & 36 & 100 & 84 & 100 & 120 & 100 \\
\hline
\end{tabular}

Source: own computation from Survey data (2019)

The average age of the research writing participant and non-participant were 42.56 and 39.75 years, respectively. With the mean difference of 2.81 between the participants and non-participants there is statistically significant difference at $10 \%$ significance level. Comparing participation in research versus non-participation in terms of work experience there is statistically significant difference between the two groups at $1 \%$ level of significances. Therefore, the null hypothesis Ho: diff $=$ mean $(0)-$ mean $(1)=0$ is rejected at all $1 \%, 5 \%$ and $10 \%$ level of significance and 118 degrees of freedom against the alternative hypothesis Ha: Ho is not true.

The average teaching load of the research participant and non-participant were 14.47 and 22.07 hours, respectively. With the mean difference of 7.599 between the participants and non-participants there is statistically significant difference at $1 \%$ significance level. It is found those staff members who reported having heavy teaching loads were less likely to participate in research. This result supports the findings of Hesli \& Lee (2011). Comparing staff participation in research versus non-participation in terms of the number of trainings participated there is statistically insignificant difference between the two groups at all $1 \%, 5 \%$ and $10 \%$ level of significances. Table 3: Participation Distribution of the academic staffs by mean difference for variables

\begin{tabular}{|c|c|c|c|c|c|}
\hline S.No & Item & Participants & $\begin{array}{c}\text { Non- } \\
\text { participants }\end{array}$ & \multirow{2}{*}{$\begin{array}{c}\text { Mean } \\
\text { difference }\end{array}$} & $\begin{array}{c}\text { t-ratio for } \\
\text { Mean difference }\end{array}$ \\
\cline { 3 - 4 } & Age & 42.5600 & 39.7500 & 2.8100 & $-1.3990^{*}$ \\
\hline 1 & Expean & Mean & -4.93254 & $-7.6948^{* * *}$ \\
\hline 2 & Exience & 8.8611 & 3.9286 & 7.5990 & $5.7651^{* * *}$ \\
\hline 3 & Teaching Load & 14.4700 & 22.07 & -0.29762 & -1.1914 \\
\hline 4 & no of trainings & 1 & 0.702381 & & \\
\hline
\end{tabular}

Source: own computation from survey (2019)

$* * *, * *$ and $*$ are statistically significant at $1 \%, 5 \%$ and $10 \%$ significance levels, respectively

From the total 120 respondents $112(93.33 \%)$ staffs do not have electronic library access while the remaining $8(6.67 \%)$ have access. From these, $33(91.67 \%)$ research wrinting participants do not have access to electronic library while only $3(8.33 \%)$ do have access. Similarly, $101(84.17 \%)$ respondents do not have access to good internet while the rest $19(15.83 \%)$ have access to good internet. $28(77.78 \%)$ of the research participants do not have access to good internet speed while only $8(22.22 \%)$ of the participants have access to internet service. Out of the total 120 sample respondents, $75(62.50 \%)$ replied that there is no enough research fund while $45(37.50 \%)$ of the staffs replied that there is enough research fund. Of the 36 research particpants, 21 (58.33\%) replied that they do not get enough research fund while $15(41.67 \%)$ replied that they get enough research fund. Similarly, Of the 84, non-participants, $54(64.29 \%)$ do not get enough research fund while 30(35.71\%) replied that there is enough research fund to participate in research.

\subsection{Hypothesis testing}

The first hypothesis testing is that the coefficients on the academic staffs' research participation variables are simultaneously equal to zero, $\beta_{1}=\beta_{2}=\ldots=\beta_{14}=0$. To test this hypothesis the log likelihood ratio is computed with the help of the log likelihood function under the null hypothesis (where all the explanatory variables of research participation are simultaneously equal to zero) and a model under the alternate hypothesis with all explanatory variables different from zero. The calculated value of LR equals to 83.212 while the critical value of LR, $\chi \mathrm{c}^{2}$, at 14 degrees of freedom with upper $1 \%, 5 \%$ and $10 \%$ significance levels, equals to $4.66,6.57$ and 7.79 , respectively. Since, these critical LR values are much less than the computed LR value at 14 degrees of freedom with all significance levels, the null hypothesis that all coefficients on the research participation model are simultaneously equal to zero is highly rejected at all the above significance levels. Thus, the explanatory variables associated with the research participation logit model are jointly significant and hence, they jointly explain research participation 
differences between the participant and non-participant staff.

The second hypothesis that the test for the joint significance of mean teaching load and work experience-in years in the logit model i.e. whether the coefficients of teaching load and work experience are simultaneously equal to zero, $\alpha_{1}=\alpha_{2}=0$. The calculated value of LR equals to 58.40 while the critical values of LR, $\chi \mathrm{c}^{2}$, at 2 degrees of freedom with upper $1 \%, 5 \%$ and $10 \%$ significance levels equal to $0.0201,0.1026$ and 0.2107 . Since, these critical LR values are less than the computed value at 2 degrees of freedom with upper $1 \%, 5 \%$ and $10 \%$ significance levels, the null hypothesis that all coefficients of the teaching load and work experience in the research participation logit model are simultaneously equal to zero is rejected. Thus, the teaching load and work experience in years associated with the research participation logit model are jointly significant and hence, they should be included in the model.

The third hypothesis is that the coefficients on the institutional determinants of research participation variables (availability of publication incentives, availability of electronic library, speed of internet, accessibility to research funds, teaching load in hours and promotion) are simultaneously equal to zero, $\delta_{1}=\delta_{2}=\ldots=\delta_{6}=0$. The calculated value of LR equals to 26.768 while the critical value of LR, $\chi c^{2}$, at 6 degrees of freedom with upper $1 \%$, $5 \%$ and $10 \%$ significance levels equals to $0.872085,1.63539$ and 2.20413 . Since, these critical LR values are less than the computed LR ratio value at 6 degrees of freedom with upper $1 \%, 5 \%$ and $10 \%$ significance levels, the null hypothesis is rejected. Thus, the institutional explanatory variables associated with the research participation logit model are jointly significant and hence, they should be included in the model since they jointly explain research participation differences between the academic staffs.

The fourth hypothesis is that the test for the joint significance of age and gender of respondent in the logit model $\left(\mathrm{H}_{0}: \phi_{1}=\phi_{2}=0\right.$ against $\mathrm{H}_{1}: \phi_{1}=\phi_{2} \neq 0$. The calculated value of LR equals to 22.933 while the critical values of LR, $\chi \mathrm{c}^{2}$, at 2 degrees of freedom with upper $1 \%, 5 \%$ and $10 \%$ significance levels equal to $0.0201,0.1026$ and 0.2107 , respectively. Since, these critical LR ratio values are much less than the computed LR ratio value at 2 degrees of freedom with upper $1 \%, 5 \%$ and $10 \%$ significance levels, the null hypothesis is rejected at all $1 \%, 5 \%$ and $10 \%$ significance levels.

Table 4: summary results of LR test of hypotheses for the aforementioned results

\begin{tabular}{|c|c|c|c|}
\hline Null hypothesis & Calculated LR ratio & Critical LR at 5\% level & Decision rule \\
\hline$\beta_{1}=\beta_{2}=\ldots=\beta_{14}=0$ & 83.212 & 6.57 & Reject Ho \\
\hline$\alpha_{1}=\alpha_{2}=0$ & 58.40 & 0.1026 & Reject Ho \\
\hline$\delta_{1}=\delta_{2}=\ldots=\delta_{6}=0$ & 26.767 & 1.63539 & Reject Ho \\
\hline$\phi_{1}=\phi_{2}=0$ & 22.933 & 0.1026 & Reject Ho \\
\hline
\end{tabular}

Source: Own computation from survey data (2019)

\subsection{Model Estimates}

The coefficient estimates from the binary logit model for research participation for academic staffs is shown in table 5.We present coefficients to identify the relevant statistically significant predictors and marginal effects to discuss the magnitudes of the effects using predicted probabilities. The results of the maximum likelihood estimation of the logit model showed that from fourteen variables such as age, gender, years of work experience, publication incentives, accessibility to research funds, teaching load in hours per year, colleague collaboration on research productivity and speed of internet have significant effect on the probability of academic staffs' research participation decision. On the other hand, availability of electronic library resources, online access of journals, availability of supervisor, number of research training, promotion and availability of national workshops are turned out to be insignificant at less or equal to 10 percent significance levels. 
Table 5: Coefficient estimates from binary logit on research participation of academic staff.

\begin{tabular}{|c|c|c|c|c|c|c|c|}
\hline $\mathrm{Yi}$ & Coef. & St.Err. & t-value & p-value & \multicolumn{2}{|c|}{ [95\% Conf Interval] } & Sig \\
\hline age & -0.166 & 0.051 & -3.27 & 0.001 & -0.266 & -0.066 & $* * *$ \\
\hline gender & -1.642 & 0.881 & -1.87 & 0.062 & -3.368 & 0.084 & $*$ \\
\hline pincent & 2.630 & 0.900 & 2.92 & 0.003 & 0.867 & 4.393 & $* * *$ \\
\hline exper & 0.675 & 0.181 & 3.72 & 0.000 & 0.319 & 1.030 & $* * *$ \\
\hline elibrar & 1.225 & 1.382 & 0.89 & 0.376 & -1.484 & 3.934 & \\
\hline tload & -0.141 & 0.068 & -2.06 & 0.039 & -0.275 & -0.007 & $* *$ \\
\hline internet & 2.764 & 1.119 & 2.47 & 0.014 & 0.570 & 4.958 & $* *$ \\
\hline nrtrain & -0.203 & 0.306 & -0.66 & 0.507 & -0.803 & 0.397 & \\
\hline superv & -0.884 & 0.952 & -0.93 & 0.353 & -2.749 & 0.982 & \\
\hline promtion & 0.919 & 0.875 & 1.05 & 0.294 & -0.796 & 2.634 & \\
\hline journ & 0.952 & 0.782 & 1.22 & 0.223 & -0.581 & 2.485 & \\
\hline worshop & -0.737 & 0.750 & -0.98 & 0.326 & -2.207 & 0.733 & \\
\hline arfund & 2.277 & 0.959 & 2.37 & 0.018 & 0.396 & 4.158 & $* *$ \\
\hline collgue & 1.625 & 0.918 & 1.77 & 0.077 & -0.174 & 3.424 & $*$ \\
\hline Constant & 1.687 & 2.934 & 0.57 & 0.565 & -4.064 & 7.438 & \\
\hline \multicolumn{2}{|c|}{ Mean dependent var } & \multicolumn{2}{|c|}{0.300} & \multicolumn{2}{|c|}{ SD dependent var } & 0.460 & \\
\hline \multicolumn{2}{|c|}{ Pseudo r-squared } & \multicolumn{2}{|c|}{0.548} & \multicolumn{2}{|c|}{ Number of obs } & 120.000 & \\
\hline \multicolumn{2}{|c|}{ Chi-square } & \multicolumn{2}{|c|}{80.331} & \multicolumn{2}{|c|}{ Prob $>$ chi 2} & 0.000 & \\
\hline \multicolumn{2}{|c|}{ Akaike crit. (AIC) } & \multicolumn{2}{|c|}{96.276} & \multicolumn{2}{|c|}{ Bayesian crit. (BIC) } & 138.088 & \\
\hline
\end{tabular}

Source: Stata output from survey data (2019)

Table 6:Marginal effects after logit $\mathrm{y}=\operatorname{Pr}($ Yi) $($ predict $)=0.16705331$

\begin{tabular}{|c|c|c|c|c|c|c|c|}
\hline variable & $\mathrm{dy} / \mathrm{dx}$ & Std.Err. & $\mathrm{Z}$ & $\mathrm{P}>\mathrm{Z}$ & {$[95 \%$ C.I $]$} & $\begin{array}{c}\text { Average } \\
\text { Value }\end{array}$ \\
\hline age & -0.023 & 0.007 & -3.120 & 0.002 & -0.038 & -0.009 & 40.725 \\
\hline gender* & -0.265 & 0.161 & -1.650 & 0.100 & -0.581 & 0.051 & 0.642 \\
\hline pincent* & 0.406 & 0.140 & 2.910 & 0.004 & 0.133 & 0.680 & 0.442 \\
\hline exper & 0.094 & 0.029 & 3.210 & 0.001 & 0.037 & 0.151 & 5.408 \\
\hline elibrar* & 0.230 & 0.315 & 0.730 & 0.464 & -0.387 & 0.847 & 0.067 \\
\hline tload & -0.020 & 0.010 & -2.010 & 0.045 & -0.039 & -0.000 & 19.792 \\
\hline internet* & 0.558 & 0.219 & 2.550 & 0.011 & 0.129 & 0.987 & 0.158 \\
\hline nrtrain & -0.028 & 0.044 & -0.650 & 0.517 & -0.114 & 0.057 & 0.792 \\
\hline superv* & -0.142 & 0.172 & -0.830 & 0.407 & -0.478 & 0.194 & 0.758 \\
\hline promtion & 0.128 & 0.121 & 1.060 & 0.291 & -0.110 & 0.365 & 0.817 \\
\hline journ* & 0.127 & 0.103 & 1.240 & 0.215 & -0.074 & 0.328 & 0.575 \\
\hline worshop* & -0.110 & 0.119 & -0.930 & 0.355 & -0.343 & 0.123 & 0.642 \\
\hline arfund* & 0.376 & 0.169 & 2.220 & 0.026 & 0.044 & 0.707 & 0.375 \\
\hline collgue* & 0.186 & 0.089 & 2.090 & 0.036 & 0.012 & 0.360 & 0.7 \\
\hline
\end{tabular}

$\left.{ }^{*}\right) \mathrm{dy} / \mathrm{dx}$ is for discrete change of dummy variable from 0 to 1

The coefficient of age is significant at $1 \%$ level of significance and it is influencing research participation negatively. A one year increase in age of a respondent has a lesser probability to involve in research. The marginal effect result shows that, a one-year increase in age of the academic staff from the average of 41 to 42 years decreases the probability of research participation by $2.3 \%$, other factors remaining constant. The result revealed that female academics participate less than their male counterparts, which might be explained in terms of female's social roles somehow impeding their decision to participate in research. The coefficient of gender is significant at $10 \%$ significance level influencing research participation negatively. Male academics have higher participation in research compared to female academics. In addition females of the study area have a lesser probability to involve in research because female academics have more responsibilities at home. In addition, females are more involved in regular household activities than males.

Furthermore, availability of publication incentives, work experience, speed of internet, accessibility to research funds and colleague collaboration on research participation all enhance the probability of academic staff's research participation while teaching load is negatively related to the probability of academic staff's research participation in the study area. 


\section{References}

Abouchedid, K. \&Abdelnour, G. (2015). Faculty research productivity in six Arab countries. International Review of Education, 61(5), 673-690.

Alzahrani, J. (2011). Overcoming Barriers to improve research productivity in Saudi Arabia. International Journal of Business and Social Science, 2(19), 50-57.

Angaiz, D. (2015). An investigation of teachers' education faculty research productivity in public sector universities of Pakistan. Unpublished doctoral dissertation, Dowling College, New York, USA

Babalola, G. A. (2014). Influence of Job Motivation, Demographic and Environmental Factors on the Productivity of Librarians in Colleges of Education in Nigeria. International journal of social relevance and concern 2(2): 23-35.

Bazeley, P. (2010). Conceptualizing research performance. Studies in Higher Education, 35(8), 889-903.

Belay \& Reji, (2016). Characteristics of a Productive Research Environment: Literature Review. Academic Medicine.

Bunting I (2014a). Academic Core Indicators as Mechanisms for Differentiation. Presentation made to the seminar: 'Where are we and what can we do?' Stellenbosch,October 2014

Chandra, (2018): Research in Universities and Economic Development in Africa. Cape Town: Centre for Higher Education Transformation

Edgar, F. \& Geare, A. (2013). Factors influencing university research performance. Studies in Higher Education, $38(5), 774-792$.

Fennewald, J. (2012). Research Productivity among Librarians: Factors Leading to Publications at Penn State. College and Research Libraries 69(2): 104-116.

Frantz J. M., A., Phillips J. (2016). 'Research Productivity of Academics in A Physiotherapy Department: A Case Study' African Journal of Health Professions Education, Vol. 2 (1).

Habtamu, D., Teka F. (2018): Assessment of the evaluation of the determinants of participation in research in Ethiopian Universities.

Hedjazi, Y., \& Behravan, J. (2011). Study of factors influencing research productivity of agriculture faculty members in Iran. Higher Education,

Hesli \& Lee. (2011): Analysis of the determinants of research participation: Cross sectional data

Hora; Merera \& Jalel, (2019). Success in research: Factors that contribute to increased research productivity across librarianship and other disciplines. Paper presented at Annual Conference of CAIS, Canadian Association for Information Science, HaramayaUniversity

John, (2017). Effects of staff participation in research on Education quality: Conclusion from a critical review of the literature review

Jung, J. (2014). Research Productivity by Career Stage among Korean Academics, Tertiary Education and Management.

Mamiseishvili \& Rosser, (2011), Jonathan M. at el, (2017). Factors affecting research productivity in public universities of Kenya: The case of Moi University, Eldoret. Journal of Emerging Trends in Economics and Management Sciences

Maassen P (2012). Universities and the effects of external funding: Sub- Saharan Africa and the Nordic countries. In: AR Nelson \& IP Wei (eds) The Global University: Past, present and future perspectives. New York: Palgrave,

Mamiseishvili, K., Rosser, V. (2011). Examining the relationship between faculty productivity and job satisfaction. Journal of the Professoriate, 5(2), 100-132.

Matthews, D. (2016). The World University Rankings. Retrieved October 21, 2017, from Research Quality Declines with Scientists' Age, Study Finds:

Mazzucato M (2013): The Entrepreneurial State: Debunking public vs. private sector myths. London: Anthem

McGill \& Settle. (2012): Publish or perish: A systematic review of interventions to increase academic publication rates. Higher Education Research and Development 25(1): 19-35.

Musiige, J., White et al. (2012). Higher Education Research: The International Journal of Higher Education

Ogoti Evans Okendo(2018) Constraints of research productivity in universities in Tanzania: a case of mwenge catholic university, Tanzania, International Journal of Education and Research Vol. 6 No. 3 March 2018

Shimelis \& Fayera, (2018). Correlational Analysis of Factors affecting Research Productivity of Ethiopian Public Universities, International Journal of Advanced Research 2018, 4(3): 40-50

Sulo et al., (2012), Shin, J. C., \& Cummings, W. K. (2010). Multi-level analysis of academic publishing across discipline: Research performance and time on research. Scientometrics

Teka F\& Habtamu A. et al, (2017). Research productivity of academics in Jigjiga University, Ethiopia.

Ubogu F \& Van den Heever M (2014). Collaboration on academic research support among five African universities. Qualitative and Quantitative Methods in Libraries

Webber, Alghanim \& Alhamali, (2011); Jung, (2012). A Mediated Hierarchical Regression Analysis of Factors 
Related to Research Productivity of Human Resource Development Post secondary Faculty. Louisiana State University.

Webber, 2012; Shariatmadari \& Mahdi, 2012; Jung, 2012). An Analysis of Factors Associated with Research Productivity of Human Resource Development Faculty. Proceedings of the Academy of Resource Development, USA.

Zeleza P (2014) The Development of STEM in Africa: Mobilizing the potential of the diaspora. Paper presented at the third annual conference on 'Effective US Strategic for African STEM Collaborations, Capacity Building, and Diaspora Engagement.' University of Michigan, Michigan, 1- 4 April 2014

Volkwein, Zhou, J. (2014) Problems teachers face when doing action research and finding possible solutions. Chinese Education \& Society. 